\title{
ESTIMATIVA PRELIMINAR DE ZONAS SATURAÇÃO DO RELEVO: UMA COMPARAÇÃO ENTRE DIFERENTES MÉTODOS
}

\author{
Jéssica Gerente ${ }^{(a)}$, Edna Lindaura Luiz ${ }^{(b)}$, Roberto Arnaldo Trancoso Gomes ${ }^{(c)}$ \\ (a) Divisão de Sensoriamento Remoto/Instituto Nacional de Pesquisas Espaciais (INPE), jessica.gerente @inpe.br \\ (b) Departamento de Geografia/Centro de Ciências Humanas e da Educação, Universidade do Estado de Santa \\ Catarina (UDESC), elinluiz@uol.com.br \\ (c) Departamento de Geografia/Instituto de Ciências Humanas, Universidade de Brasília (UnB), \\ robertogomes@unb.br
}

\section{Eixo: GEOGRAFIA FÍSICA E DESASTRES NATURAIS}

\begin{abstract}
Resumo
Zonas saturadas no relevo podem condicionar movimentos de massa. A topografia influencia na convergência ou divergência de fluxos. A partir de MDEs é possível extrair informações sobre o potencial de uma área para ocorrência de processos erosivos. Modelos matemáticos permitem criar diferentes cenários, onde as condições ambientais podem ser calibradas. Neste trabalho, o modelo TOPOG foi utilizado para estimar as zonas que possuem condições de saturação na bacia do rio Luís Alves/SC. Foram testados três métodos de acumulação de fluxo para entrada no modelo, considerando precipitação de $250 \mathrm{~mm} /$ dia. Devido ao tamanho da bacia, heterogeneidade e profundidade do solo, foram testados três diferentes valores de transmissividade. Sobrepondo os resultados com um inventário de cicatriz de movimentos de massa, percebe-se que considerável parte deles ocorreu em áreas classificadas como suscetíveis a saturação. Os métodos D-infinito e MDF foram os mais adequados para a estimação preliminar das zonas saturadas na área de estudo.
\end{abstract}

Palavras chave: zonas saturadas, acumulação de fluxo, movimentos de massa.

\section{Introdução}

A saturação das formações superficiais (solos, regolito, depósitos) que recobrem as formas de relevo pode condicionar a geração de diferentes processos erosivos (movimentos de massa, inundações, fluxos torrenciais e etc). Estes processos muitas vezes podem representar perigo para os seres humanos e suas materializações na paisagem. O fenômeno da saturação ocorre pelo completo preenchimento dos poros dos mantos de alteração por água que chega tanto pela infiltração direta quanto por fluxos laterais ou ascendentes. Contribui para isso, a quantidade de chuva que cai no local, a condutividade hidráulica dos materiais que compõem o relevo, a organização destes materiais e ainda a declividade e a forma dos terrenos (topografia). Desses fatores condicionantes de formação de zonas saturadas, as características da chuva (quantidade, duração e intensidade) é o que mais varia mais ao longo do tempo. Episódios de chuva com características diferentes podem criar ou não zonas saturadas ou até mesmo fazer variar a localização destas zonas ao longo de uma paisagem. 
A modelagem matemática de previsão e identificação de áreas saturadas aparece como uma alternativa eficaz e de baixo custo para o conhecimento preliminar das áreas do relevo mais propensas a atingir a condição de saturação. $\mathrm{Na}$ modelagem, é possível construir diferentes cenários, variando tanto as propriedades dos materiais que compõem os terrenos (condutividade hidráulica, textura, estrutura, etc.) como as características da chuva. Assim como na natureza, nos modelos matemáticos a topografia é um importante aspecto para o condicionamento de áreas mais ou menos suscetíveis a saturação. A topografia, diferentemente de outros fatores mais específicos ligados às propriedades químicas e físicas dos materiais, pode ser representada digitalmente de modo satisfatório e acessível.

Um modelo digital de terreno (MDT) não representa apenas digitalmente a topografia. Ele possibilita a extração de informações do relevo como forma, declividade, direção e acumulação de fluxo, as quais são muito importantes para a modelagem de processos erosivos. Além disto, para muitos modelos de previsão a movimentos de massa e zonas saturadas, o MDT é um dos dados distribuídos de mais facilmente obtido. No Brasil, o modelo de saturação proposto por O’Loughlin (TOPOG) demonstrou bons resultados para aplicação na previsão de inundação (SANTI, 2004; DAMACENA et al., 2009). Contudo, este modelo pode ser também aplicado para a identificação de zonas de saturação e isto pode auxiliar o diagnóstico e mapeamento da suscetibilidade a movimentos de massa e escoamento superficial concentrado.

Neste trabalho, o TOPOG foi utilizado para o reconhecimento das zonas que possuem condições de saturação na bacia do rio Luís Alves/SC. Foram analisados os resultados do modelo utilizando três diferentes algoritmos de acumulação de fluxo com a finalidade de reconhecer as áreas mais críticas (que seriam as que saturam por todos os métodos) e também para verificar as diferenças entre os resultados gerados. Esta bacia foi escolhida em função das precipitações excepcionais que ali ocorreram em novembro de 2008, as quais provocaram grande quantidade de movimentos de massa, inundações e fluxos torrenciais, processos que sofrem influência da formação de zonas saturadas. Em função da falta de estudos de predição e da recorrência destes processos na bacia do rio Luís Alves, a aplicação deste modelo se mostra interessante para diagnósticos preliminares.

\subsection{Modelo de Identificação de Zonas de Saturação de O’Loughlin (1986): TOPOG}

O modelo de O'Loughlin (1986) utiliza o conceito de área de contribuição baseada na topografia. Esta ideia partiu Beven e Kirkby (1979) que comprovaram a importância da área de contribuição e da declividade para estimar o índice de umidade de um terreno. Eles criaram um modelo hidrológico topograficamente baseado denominado de TOPMODEL. Em um sistema de informações geográficas, o TOPMODEL demonstra que o padrão de saturação em um determinado ponto a jusante está relacionado com a área de contribuição (razão a/b), ou seja, a quantidade de água que passa por uma célula, sendo que 
o resultado desta divisão ainda é dividido pelo ângulo de inclinação da encosta $(\theta)$ (O'LOUGHLIN, 1986). O potencial de saturação de um ponto seria então diretamente dependente de sua posição na bacia hidrográfica (O’LOUGHLIN, 1986).

A relação (a/b) / $\theta$ proposta por Beven e Kirkby (1979), vem sendo incorporada em diversos modelos hidrológicos e de estabilidade de encostas, como é o caso do modelo de identificação de zonas saturadas de O'Loughlin (1986), conhecido como TOPOG e do modelo de previsão a deslizamentos rasos de Montgomery e Dietrich (1994), conhecido como SHALSTAB. O TOPOG é um modelo hidrológico que estima o grau de saturação do solo em resposta a uma dada precipitação e transmissividade.

Assim como o TOPMODEL, o TOPOG é um modelo hidrológico de estado uniforme (Steady State), pois assume uma quantidade de recarga de chuva uniforme para toda a bacia para simular a variabilidade espacial da altura da coluna d'água (que poderá gerar uma condição de saturação) do manto de alteração e/ou solo. O TOPOG considera que uma superfície possui condições de saturação se o produto da área de contribuição (a/b) multiplicada por uma determinada quantidade de chuva (q) for maior ou igual ao produto da transmissividade saturada $(\mathrm{T})$ do manto de alteração do terreno pelo seno do ângulo de sua inclinação $(\theta)$ : “ a/b .q $\geq \mathrm{T}$. seno $\theta$ ”. Sendo assim, a condição de saturação pode ser representada por um índice de umidade "W" (SANTI, 2004): "W = q / T . (a/b) / seno $\theta$ ". Nele, os valores superiores a 01 indicam condições suficientes de saturação (DAMACENA et. al., 2009).

O TOPOG assume que a infiltração ocorre até uma camada de solo impermeável (como o contato manto de alteração-rocha). A partir desta condição, a continuação da infiltração aumentará a coluna d'água do solo, criando assim zonas de saturação. Estas zonas de saturação poderão produzir fluxos que seguem lateralmente na encosta de acordo com a topografia, pois o modelo assume a presença de condutividade hidráulica saturada para jusante. O TOPOG utiliza parâmetros extraídos de um modelo digital de terreno (área de contribuição e declividade), além de valores de transmissividade e precipitação que podem ser obtidos por observações de campo ou dados secundários. A transmissividade representa a capacidade de transmitir água ao longo do solo/manto de alteração e é obtida pelo produto da permeabilidade com a profundidade (SANTI, 2004).

A topografia é um aspecto de grande influência na direção do escoamento de um terreno (GRUBER e PECKHAM, 2009). A partir de um MDT é possível obter a direção do fluxo e, deste, a área de contribuição (razão a/b) do TOPOG. Métodos que utilizam uma transferência de fluxo distribuída tendem a produzir padrões de drenagem mais realísticos do que os unidirecionais (ALI et al., 2014), pois consideram a existência de caminhos de fluxo preferenciais (RAMOS et al., 2003). 
Uma das metodologias pioneiras para a determinação da direção de fluxo foi elaborada por O'Callaghan e Mark (1984). Denominado de D8, o método criado por eles calcula o fluxo da bacia em uma direção unitária e é o mais comumente usado (ERSKINE et. al., 2006). Por este método, o fluxo de uma determinada célula é transferido para uma das oito células adjacentes, sendo a célula que possuir a menor elevação em relação ao ponto central a que receberá o fluxo (O'CALLAGHAN e MARK, 1984). Este método trabalha com a convergência de fluxo (várias células drenando para uma), e não com divergência de fluxo (uma célula drenando para duas ou mais células) e é chamado de D8 devido às oito possíveis direções de drenagem (GRUBER e PECKHAM, 2009). A ferramenta "Flow Direction" do ArcGIS 10.1 utiliza o D8 para geração da direção de fluxo, a partir do qual pode-se obter a razão a/b por meio da ferramenta "Flow Accumulation".

Dentre os demais métodos de direção de fluxo, destacam-se o MFD (multiple flow direction) utilizado no TOPMODEL por Quinn et al. (1991) e o Dinf (D-infinito) desenvolvido por Tarboton (1997). Estes são exemplos de algoritmos que, ao contrário do D8, consideram duas ou mais direções de fluxo como possíveis. A metodologia MFD de Quinn et. al. (1991), como o próprio nome já explicita, calcula o escoamento do fluxo em múltiplas direções. Ela permite que o fluxo de uma dada célula seja calculado de forma distribuída para todas as células vizinhas a jusante de acordo com suas declividades (ALI et al., 2014). Pelo método multidirecional (MFD) de Quinn et al. (1991), o cálculo da área de contribuição da porção do fluxo escoado para cada pixel a jusante do central será proporcional ao produto distância caminhada e a um fator geométrico dependente da direção do fluxo (RAMOS et al., 2003).

O Dinf pode ser considerado como um método intermediário entre os unidirecionais e multidirecionais, pois permite que o fluxo escoe para uma ou duas células vizinhas. Nele, a polarização do D8 de acumulação de fluxo, bem como o excesso de dispersão para todas as células vizinhas à jusante inerentes do MFD são evitados (GRUBER e PECKHAM, 2009). Neste método, o fluxo pode drenar para uma das oito células circunvizinhas ou se dividir entre o ângulo direto formado a partir do centro de duas células vizinhas adjacentes (TARBOTON, 1997). A área de contribuição de cada pixel é dada pela soma de sua própria área com a área dos pixels à montante que drenam a este pixel, a qual corresponde ao fluxo acumulado (TARBOTON, 1997).

\section{Localização da área de estudo}

A bacia do rio Luís Alves está situada no nordeste do estado de Santa Catarina, entre as coordenadas $26^{\circ}$

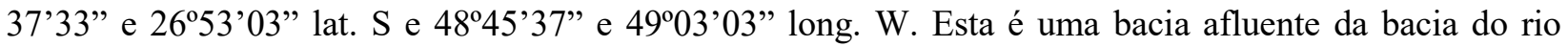
Itajaí. A área da bacia é de aproximadamente $582 \mathrm{~km}^{2}$ (Figura 01). A delimitação desta bacia foi feita a partir da base cartográfica 1:50.000 do IBGE (Instituto Brasileiro de Geografia e Estatística) cuja base foi 


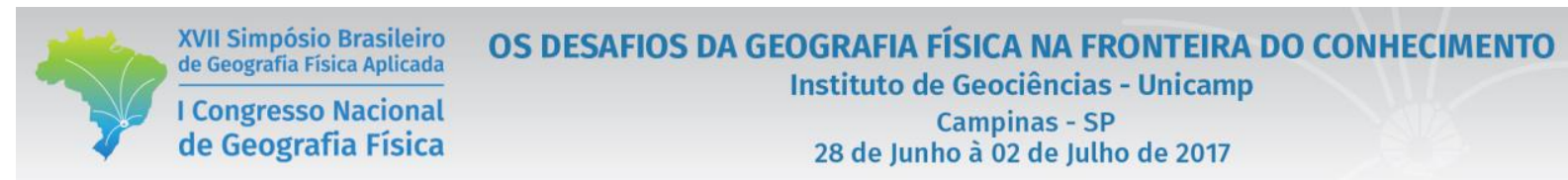

utilizada como produto bruto da geração dos dados topográficos inseridos no TOPOG. As chuvas ao longo de todo o ano nesta bacia permitem a existência de uma rede de drenagem densa e perene na bacia, com muitos trechos de rios seguindo lineamentos estruturais, pois esta é uma área de grande trabalhamento tectônico.

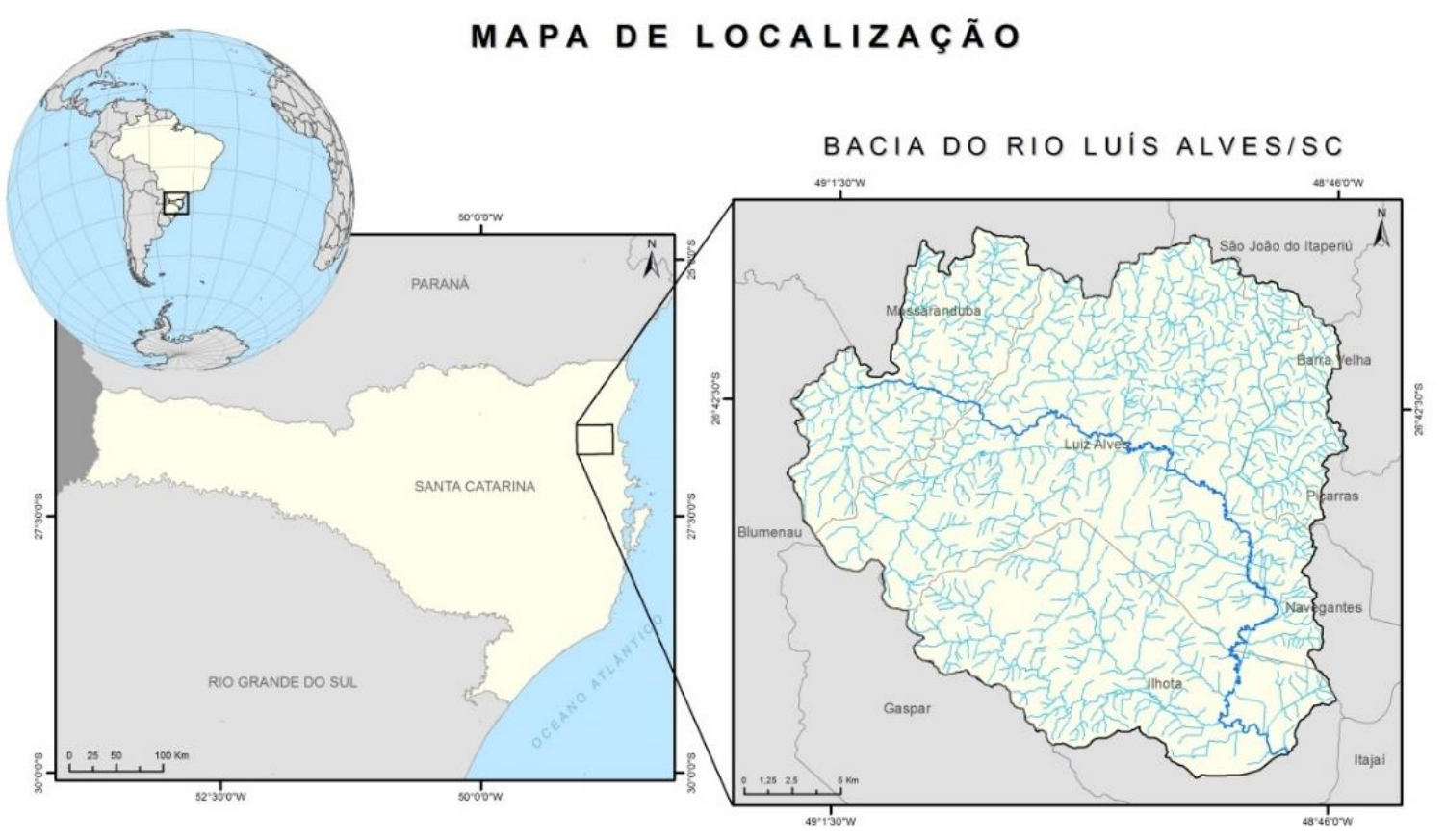

Figura 1 - Localização da área de estudo.

Fornari (1998) identificou na área que as rochas locais sofreram pelo menos dois episódios deformacionais no estado dúctil, com geração de zonas de cisalhamentos, falhas, fraturas, deformações e metamorfismo do tipo granulito. Segundo o autor, a litologia da bacia é formada por granulitos e migmatitos com associações metassedimentares, máfico-ultramáficas e enderbitos. Também ocorrem veios quartzo-feldspáticos. Estes veios e também rochas cataclasadas podem formar trechos de leitos fluviais rochosos e inclusive, quedas e corredeiras. Estas rochas produzem mantos de alteração profundos na bacia sobre os quais é modelado um relevo com dissecação em morros e montanhas com vales encaixados e diversas planícies fluviais. Há muitas planícies fluviais do tipo alveolar. As altitudes variam de aproximadamente o nível do mar, junto à foz do rio Luís Alves no rio Itajaí Açu, até mais de 800m em áreas como morro do Cachorro e morro do Baú.

Os solos da bacia são do tipo argissolo e cambissolo, contudo é possível encontrar em certos locais de rochas mais resistentes (áreas de rochas cataclásticas e veios quartzo-feldspáticos) ou em altas declividades, os neossolos litólicos. É interessante observar que há cambissolos em mantos de alteração muito profundos, ou seja, apesar do solo pouco desenvolvido, a alteração da rocha é profunda. Luiz et al. 


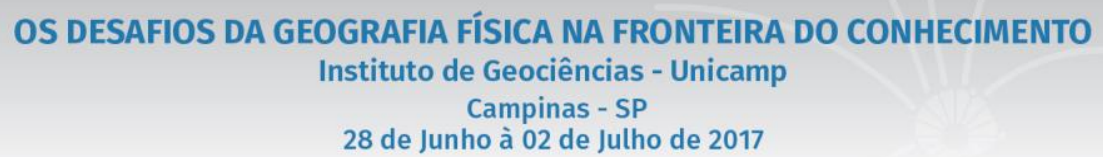

(2014) encontraram texturas muito siltosas no horizonte C de um manto alteração presente no interior de uma cicatriz de movimento de massa.

A vegetação original presente na bacia do rio Luís Alves era Floresta Ombrófila Densa, que atualmente está em regeneração em diferentes estágios, especialmente de capoeira e capoeirões. A vegetação nativa é substituída, nos fundos de vales e algumas das encostas, por reflorestamentos de Pinus Elliottii e Eucaliptos, cultivos de lavouras permanentes como bananas e palmeiras reais, além de pastagens.

\section{Materiais e Métodos}

Para a definição preliminar das zonas saturadas na bacia do rio Luís Alves foi utilizado o modelo de saturação (TOPOG) proposto por O'Loughlin (1989). Este modelo necessita de um MDT bem como valores de transmissividade do solo e de precipitação para sua resolução. Como o MDT tem grande influência no resultado do modelo de saturação de O’Loughlin, é interessante que se utilize MDTs com melhor qualidade possível.

Para avaliação dos resultados um inventário das cicatrizes de movimentos de massa deflagrados em 2008 na área de estudo foi utilizado. A elaboração deste inventário se deu por observação de imagens do aplicativo Google Earth do ano de 2009 e vetorização em tela sobre as fotografias aéreas ortorretificadas de 2011 do governo do estado de Santa Catarina. Neste mapeamento considerou-se como cicatriz tanto a zona de ruptura na encosta como o depósito. Ao todo foram mapeadas mais de 200 cicatrizes.

Para poder utilizar as cicatrizes dos movimentos de massa de 2008 como forma de avaliação, foi necessário usar um MDT realizado a partir das configurações topográficas anteriores a este evento. Em razão da deficiência de dados topográficos para região, gerou-se um MDT a partir do mapeamento sistemático do IBGE. Deste mapeamento, realizado na década de 1980 em escala 1:50.000, utilizaram-se as curvas de nível com equidistância de 20 metros, pontos cotados e rede hidrográfica das cartas Blumenau, Gaspar, Itajaí, Barra Velha, Luís Alves e Pomerode, baixadas da mapoteca digital da Empresa de Pesquisa Agropecuária e Extensão Rural de Santa Catarina (EPAGRI). Apesar de que a bacia estudada é muito menor do que a área abrangida por estas cartas, elas foram utilizadas para evitar efeitos de borda na interpolação dos dados.

Esses dados topográficos do IBGE foram corrigidos topologicamente de acordo com a metodologia adotada por Freitas (2012), sendo realizado em três etapas. A primeira foi a junção das curvas de nível e rios que entre uma articulação e outra estavam desconectados. A segunda etapa foi a correção topológica dos dados, cuja descrição de regras pode ser encontrada em Freitas (2012). Por fim, a última etapa do pré- 
processamento foi a correção do sentido do vetor dos dados de hidrografia. Alguns vetores cujo sentido deveria ser montante-jusante estavam invertidos, necessitando então de correções.

Após a correção gerou-se um MDT com 10 metros de resolução espacial pelo fato deste tamanho de pixel representar a metade da equidistância das curvas de nível. Gomes et. al. (2004) consideraram a escala (1:50.000) e resolução espacial utilizadas no presente trabalho como viáveis para mapeamentos preliminares envolvendo modelagem. O MDT foi gerado pela ferramenta "Topo to Raster" do ArcGIS 10.1, a qual combina o interpolador local "Inverso do Quadrado da Distância" (IDW) com interpoladores regionais do tipo "Krigagem" e "Spline" que se baseiam em uma superfície de continuidade. O interpolador Topo to Raster, é um dos mais indicados para usos que envolvam modelagem hidrológica (TEIXEIRA, 2012).

O MDT foi o único parâmetro distribuído inserido no modelo TOPOG, uma vez que a quantidade de chuva e a transmissividade foram colocados na equação como valores discretos. Como o intuito deste trabalho foi tentar simular o cenário de saturação do último grande desastre da região, como valor de chuva utilizou-se o dado da medição da estação pluviométrica de Blumenau/SC da Agência Nacional de Águas (ANA) do dia 24/11/08, o qual registrou 250 mm/dia. Como transmissividade, utilizaram-se três valores. O primeiro foi de $5 \mathrm{~m}^{2} /$ dia, cujo valor foi obtido com base nos dados de Luiz (2003) em análise do horizonte $\mathrm{C}$ de um manto de alteração de rochas granitoides alcalinas do município de São Pedro de Alcântara/SC e também na análise do manto de alteração em campo na bacia do rio Luís Alves. Ou outros dois valores foram $30 \mathrm{~m}^{2} /$ dia e $65 \mathrm{~m}^{2} /$ dia devido ao fato de que valores de transmissividade costumam ser muito variáveis e o próprio manto de alteração da região também possui esta heterogeneidade.

O processamento dos dados gerou nove cenários produzidos com o TOPOG a partir da combinação entre os diferentes métodos de acumulação de fluxo e valores da transmissividade acima citados. O primeiro raster de acumulação de fluxo foi gerado pelo algoritmo D8, método uni-direcional. O segundo raster de acumulação de fluxo foi gerado pelo método D-Infinito (D-inf), através da ferramenta "TauDEM" disponibilizada pela Utah State University. A última acumulação de fluxo foi gerada com o método multidirecional de Quinn (1991), MDF, por meio do software SAGA GIS. Cada um destes três rasters foi inserido como dado de entrada no TOPOG e para cada um foram testados os três valores de transmissividade e um valor fixo de precipitação.

\section{Resultados e Discussão}

O processamento de acumulação de fluxo a partir do método D8 (uni-direcional), do método D-Infinito (bi-direcional) e do método multi-direcional MDF gerou diferentes resultados. Foi possível notar que pelo método D8, o fluxo segue um padrão mais direcionado, ao contrário do de Quinn (1991) que condiciona um fluxo montante - jusante de forma mais distribuída. O resultado pelo método Dinf aparece como um 


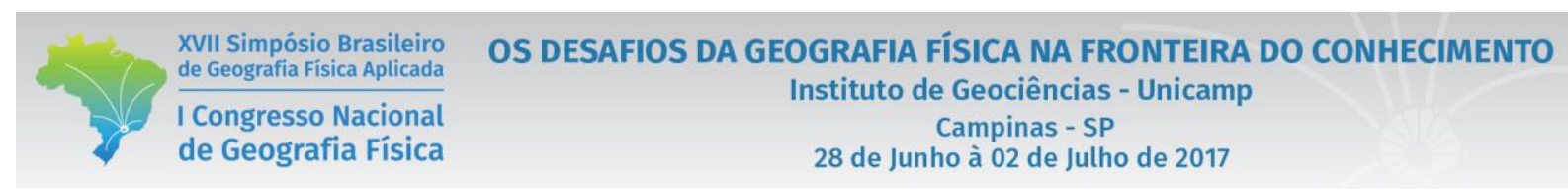

meio termo entre os outros dois. Para alguns autores, em formas de relevo mais suaves como colinas, métodos que utilizam uma transferência de fluxo distribuída tendem a produzir padrões de drenagem mais realísticos do que os unidirecionais (ALI et al., 2014), pois consideram a existência de caminhos de fluxo preferenciais (RAMOS et al., 2003). Estudos anteriores demonstraram que algoritmos direcionais se mostram superiores em zonas de fluxo convergente e grandes áreas de drenagem, com canais bem desenvolvidos (QUINN et al., 1991; MARTZ; GARBRECHT, 1992).

Como resultado da modelagem de identificação preliminar de áreas de saturação no relevo pelo modelo TOPOG, obtiveram-se os cenários apresentados na figura 02. Para o método D8, o uso da transmissividade de $5 \mathrm{~m}^{2} /$ dia mostrou que quase toda a bacia satura em chuvas de $250 \mathrm{~mm}$. Este resultado parece não ser muito realista, pois deveria ter causado mais fenômenos de movimento de massa, fluxo torrencial e inundações na bacia do que realmente ocorreu em novembro de 2008. Cenários com transmissividade de $65 \mathrm{~m}^{2} /$ dia geraram menos áreas saturadas, localizadas principalmente ao longo dos fundos dos vales. Para a transmissividade de $5 \mathrm{~m}^{2} /$ dia, a saturação ocorreu em 96,30\% da área da bacia, enquanto para as transmissividades de $30 \mathrm{~m}^{2} / \mathrm{dia}$ e $65 \mathrm{~m}^{2} / \mathrm{dia}$, o total saturado foi de $58,62 \%$ e $37,21 \%$ respectivamente (tabela 1$)$.

Tabela 1 - Quantidade de áreas saturadas e de valores mínimos e máximos calculados por cada algoritmo (D8, Dinf e MDF) e cada valor de transmissividade (05, 30 e $\left.65 \mathrm{~m}^{2} / \mathrm{dia}\right)$, considerando um evento de chuva de $250 \mathrm{~mm} / \mathrm{dia}$.

\begin{tabular}{|c|c|c|c|c|c|c|c|c|c|}
\hline \multirow{3}{*}{ Algoritmo } & \multicolumn{3}{|c|}{ Quantidade de área saturada [\%] } & \multicolumn{6}{|c|}{ Valores Mínimos e Máximos } \\
\hline & \multirow{2}{*}{$\begin{array}{c}05 \\
\mathrm{~m}^{2} / \mathrm{dia}\end{array}$} & \multirow{2}{*}{$\begin{array}{c}30 \\
\mathrm{~m}^{2} / \mathrm{dia}\end{array}$} & \multirow{2}{*}{$65 \mathrm{~m}^{2} / \mathrm{dia}$} & \multicolumn{2}{|c|}{$05 \mathrm{~m}^{2} / \mathrm{dia}$} & \multicolumn{2}{|c|}{$30 \mathrm{~m}^{2} / \mathrm{dia}$} & \multicolumn{2}{|c|}{$65 \mathrm{~m}^{2} / \mathrm{dia}$} \\
\hline & & & & Mínimo & Máximo & Mínimo & Máximo & Mínimo & Máximo \\
\hline D8 & $96,30 \%$ & $58,62 \%$ & $37,21 \%$ & $-0,4483$ & 25,8122 & $-2,2401$ & 23,9174 & $-3,0133$ & 23,1443 \\
\hline Dinf & $99,93 \%$ & $53,29 \%$ & $40,34 \%$ & 0,2838 & 24,7812 & $-1,7057$ & 26,6145 & $-2,4789$ & 25,7302 \\
\hline MDF & $99,99 \%$ & $70,71 \%$ & $45,60 \%$ & 0,2131 & 26,1659 & $-1,5786$ & 24,3741 & $-2,3517$ & 23,6009 \\
\hline
\end{tabular}

A criação de zonas saturadas pelos métodos D-Inf e MDF produziram uma maior saturação do que o método D8 para o valor de transmissividade de $5 \mathrm{~m}^{2} /$ dia. Por estes dois métodos, os quais geraram valores mínimos positivos para esta transmissividade, praticamente a área inteira da bacia satura. Para transmissividade de $30 \mathrm{~m}^{2} /$ dia, a área saturada pelo D-inf foi de 53,29\% e pelo método MDF foi de $70,71 \%$. Já para valores de $65 \mathrm{~m}^{2} /$ dia, a área saturada pelo cenário criado pelo D-inf foi de $40,34 \%$ e pelo MDF foi de $45,60 \%$.

Em relação às diferentes transmissividades analisadas, observa-se que as de $30 \mathrm{~m}^{2} / \mathrm{dia}$ e $65 \mathrm{~m}^{2} / \mathrm{dia}$ apresentaram maiores variações da quantidade de áreas que saturam na bacia entre os três métodos de acumulação de fluxo, especialmente, o cenário de $30 \mathrm{~m}^{2} /$ dia no método MDF. Aliás, este último foi o método que apresentou maior quantidade de áreas saturadas entre os três métodos utilizados. O uso de múltiplas direções para o escoamento do fluxo no método MDF talvez explique porque a área saturada 

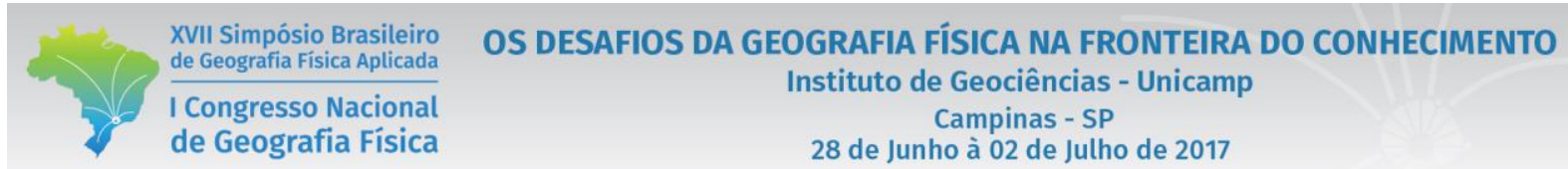

calculada para diferentes valores de transmissividade foi mais abrangente em relação aos outros métodos, uma vez que o fluxo de água de jusante para montante pelo interior do solo e/ou manto de alteração poderia seguir várias direções e assim se acumular mais em determinado ponto exutório.

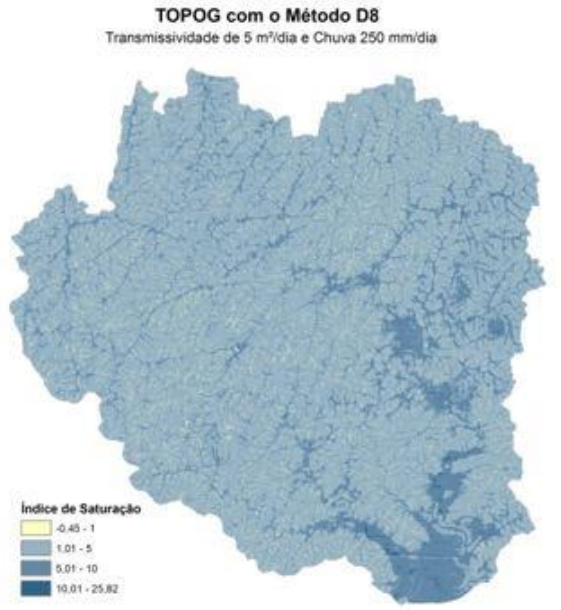

TOPOG com o Método D-Inf

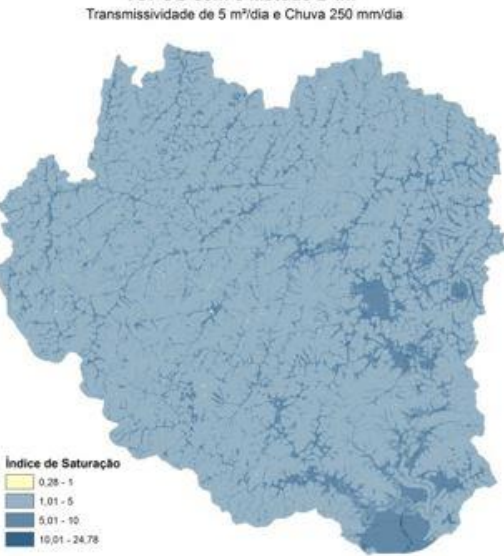

TOPOG com o Método MDF de Quinn (1991)

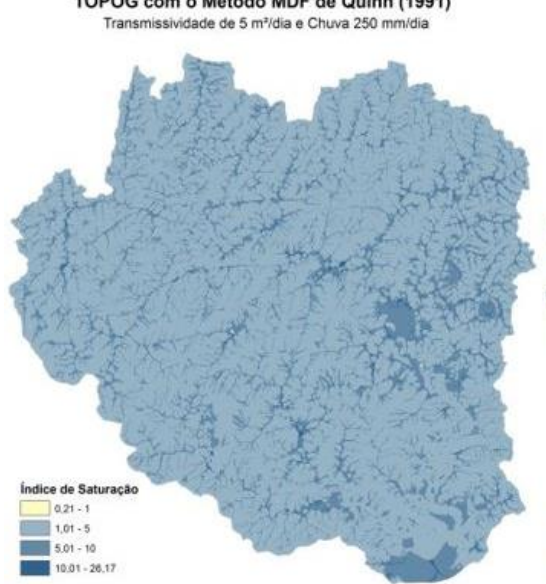

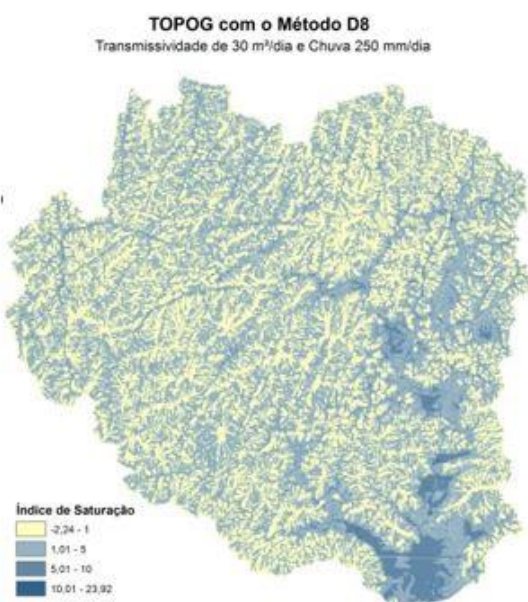

TOPOG com o Método D-Inf Transmissividade de $65 \mathrm{~m}^{3} / \mathrm{dia}$ e Chura 250 mmidia
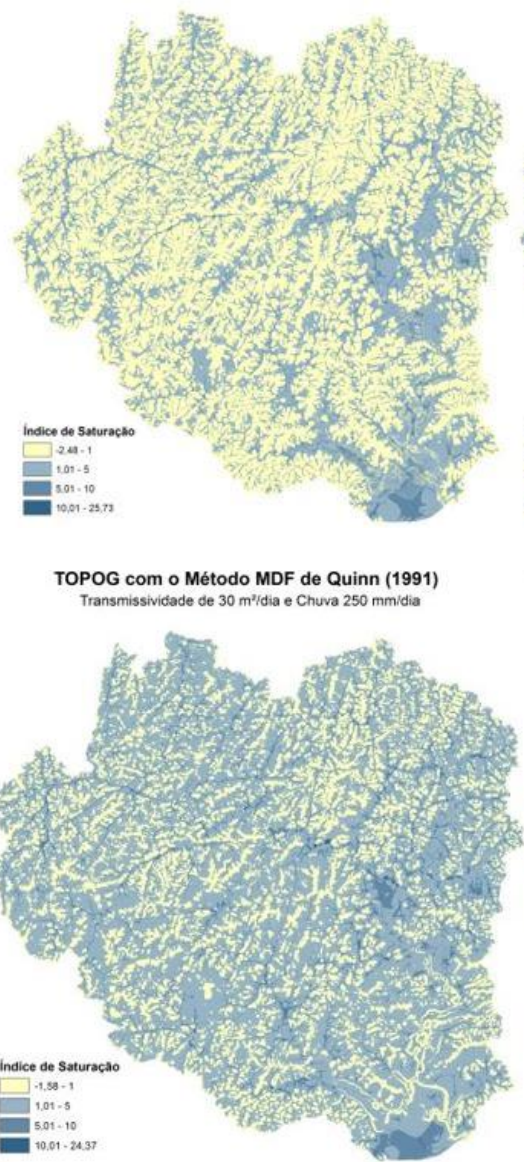

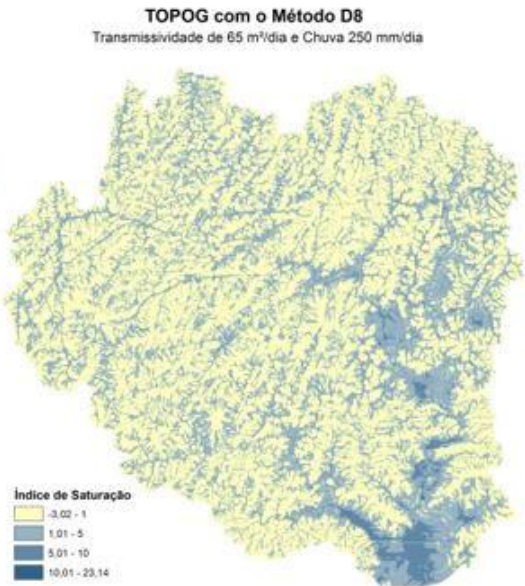

TOPOG com o Método D-Inf

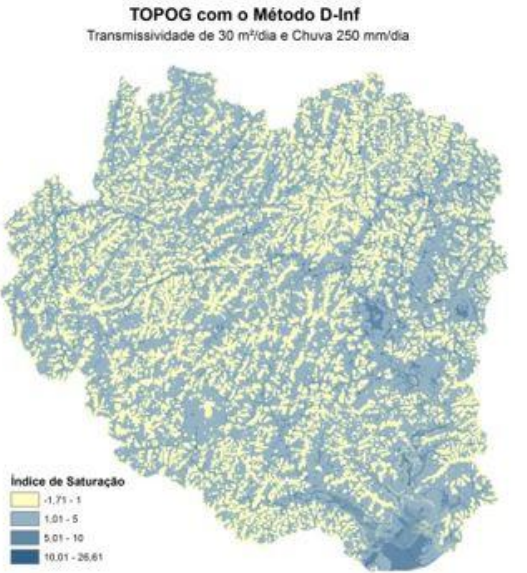

TOPOG com o Método MDF de Quinn (1991)

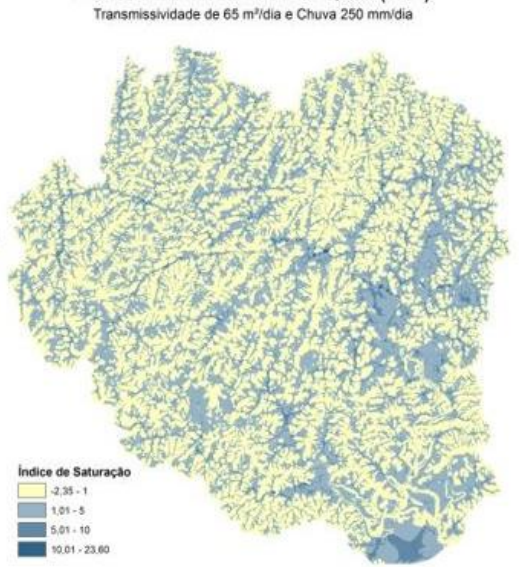

Figura 2 - Resultados do TOPOG para diferentes valores de transmissividade e métodos de acumulação de fluxo. 


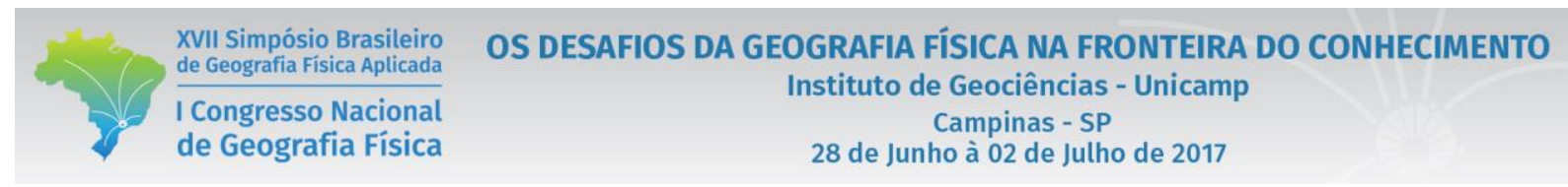

A verificação dos cenários gerados com os diferentes métodos de acumulação de fluxo e com diferentes valores de transmissividade a partir da sobreposição das cicatrizes de movimentos de massa deflagrados em novembro de 2008 na bacia do rio Luís Alves mostrou que para transmissividade de $5 \mathrm{~m}^{2} / \mathrm{dia}$, todas as cicatrizes estavam em área saturada para todos os métodos. Contudo, isto ocorre porque para esse valor de transmissividade em todos os métodos de acumulação de fluxo praticamente toda a bacia fica saturada. A validação neste caso fica inviável. Para transmissividade de $30 \mathrm{~m}^{2} /$ dia, algumas cicatrizes já não caem em zonas saturadas, principalmente para o cenário obtido com o método de MDF. Para transmissividade de $65 \mathrm{~m}^{2} /$ dia, diminui o número de cicatrizes que se localizam em zonas saturadas, especialmente para o cenário calculado pelo método D8, uma vez que este método apresentou menor área saturada para esse valor de transmissividade.

As cicatrizes de movimentos de massa deflagradas em 2008 foram sobrepostas com as áreas saturadas calculadas por cada método e valor de transmissividade (figura 03).

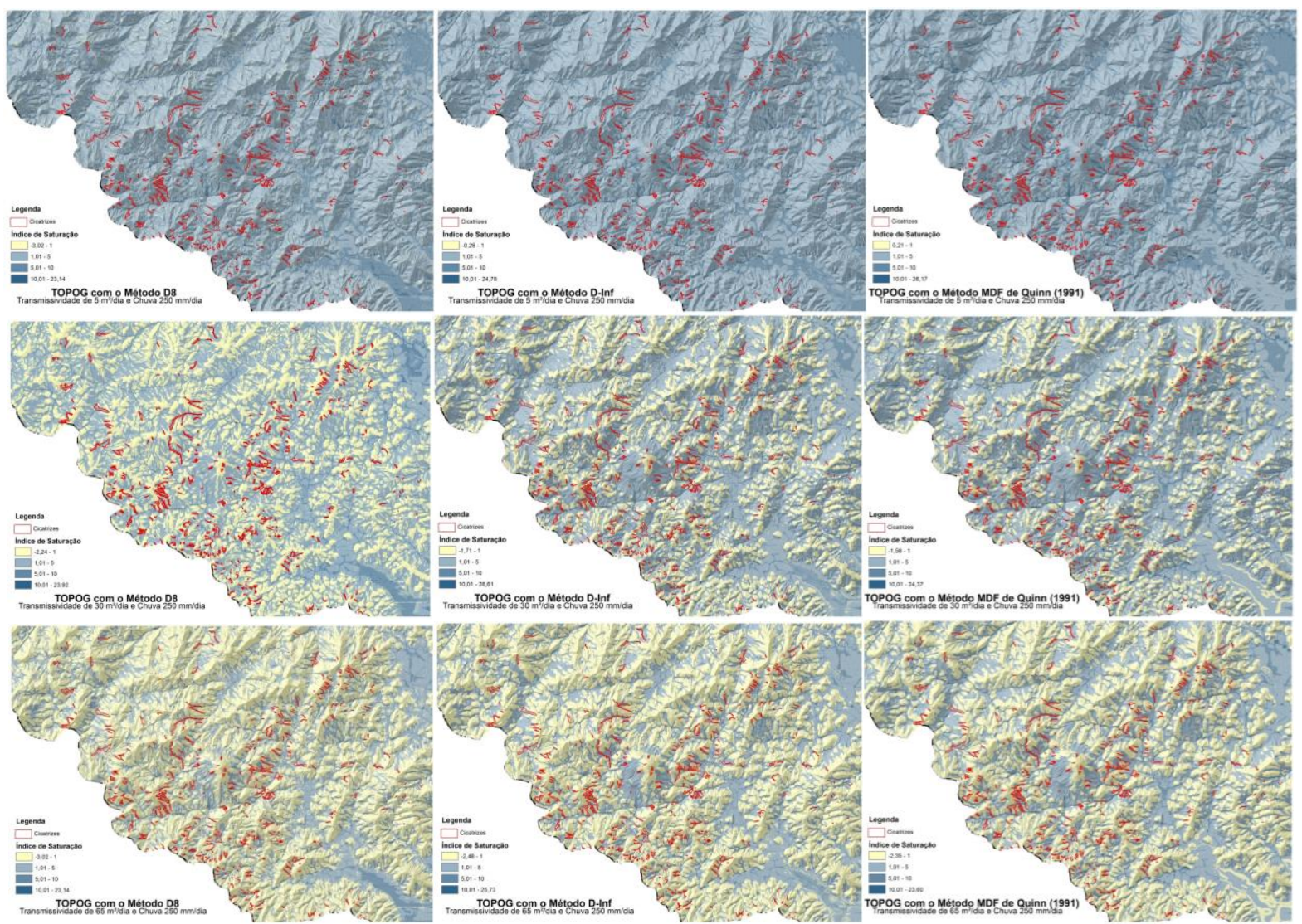

Figura 3. Sobreposição das cicatrizes de movimentos de massa nos cenários criados pelo método D8, Dinf e MDF de Quinn (1991) para transmissividades de $5 \mathrm{~m}^{2} / \mathrm{dia}, 30 \mathrm{~m}^{2} / \mathrm{dia}$ e $65 \mathrm{~m}^{2} / \mathrm{dia}$.

Percebe-se que em todos os cenários utilizando valor de transmissividade de $5 \mathrm{~m}^{2} / \mathrm{dia}$ as cicatrizes mapeadas coincidiram com áreas saturadas. Isto não corresponde à realidade, uma vez que há cicatrizes 
que com certeza não foram deflagradas apenas por perda de resistência em função da tensão efetiva. Muitas cicatrizes ocorreram por retirada de suporte basal e/ou lateral em função de erosão fluvial ou da passagem de fluxos de detritos. Para os valores de transmissividade de $30 \mathrm{~m}^{2} / \mathrm{dia}$ e $65 \mathrm{~m}^{2} / \mathrm{dia}$ algumas cicatrizes não estão em áreas saturadas, o que está de acordo com o colocado anteriormente de que nem todo movimento de massa ocorre por saturação do solo. Mas, pela quantidade de área saturada utilizando $30 \mathrm{~m}^{2} /$ dia, especialmente no cenário calculado pelo MDF, muitas cicatrizes que envolvem a forma de corrida de detritos estão em áreas saturadas. Este tipo de movimento de massa envolve o aumento do teor de água no solo, tanto no momento da ruptura quanto no seu deslocamento encosta abaixo. $\mathrm{O}$ uso do cenário com a transmissividade de $65 \mathrm{~m}^{2} /$ dia mostrou poucas cicatrizes em áreas de saturação, apesar de que no método de acumulação de fluxo do MDF é possível observar maior ocorrência de cicatrizes sobre áreas saturadas. Entretanto, este valor de transmissividade se mostra exagerado para as condições da bacia.

\section{Conclusões}

Em relação aos resultados do TOPOG gerado pelos três métodos de geração de área de acumulação testados, o método de acumulação de fluxo multidirecional (MDF) foi o que apresentou a maior quantidade de áreas saturadas para todos os valores de transmissividade. Isso já era esperado, pois como esse método direciona o fluxo de modo distribuído, a tendência é que exista uma maior área de contribuição e consequentemente uma quantidade maior de áreas saturadas. $\mathrm{O}$ valor de transmissividade de $5 \mathrm{~m}^{2} /$ dia parece ser subestimado, apesar dele ter sido obtido a partir de medidas de permeabilidade de materiais de alteração muito semelhantes ao encontrado em Luís Alves. Talvez o valor de profundidade para o cálculo da transmissividade pudesse ser aumentado, uma vez que os mantos de alteração na bacia em estudo são muito espessos.

Diante do que foi observado, o modelo que pareceu mais próximo da realidade foi o aquele com a área de contribuição multidirecional (método de Quinn, 1991) e com valor de transmissividade de $30 \mathrm{~m}^{2} / \mathrm{dia}$. Com base neste cenário, foi possível verificar que nem todas as áreas saturadas correspondem às cabeceiras das cicatrizes de movimentos de massa mapeadas. Isso pode ser explicado porque alguns movimentos de massa podem não ter surgido em razão de zonas saturadas ou porque houve rupturas posteriores nas cabeceiras das cicatrizes que a posicionaram mais a montante de sua origem. Aponta-se, entretanto, para trabalhos futuros, a necessidade de maiores investigações em campo a fim de calibrar e melhor validar o modelo.

\section{Bibliografia}

ALI, G., BIRKEL, C., TETZlAFF, D., SOUlSBY, C., MCDONNELl, J. J. AND TAROLLI, P. 2014, A comparison of wetness indices for the prediction of observed connected saturated areas under contrasting conditions. Earth Surface Process and Landforms, nº. 39, p.399 - 413. 
BEVEN, K. K. e KIRKBY, M.J. 1979, A physically based, variable contribuing area model of basin hydrology,Hydrology Sciences - Bulletin des Sciencies Hydrologiques, v.24, p. 43-69.

DAMACENA, F. A.; GUIMARÃES, R. F.; CATÃO, R. de C.; GOMES, R. A. T. et al. 2009, Identificação de zonas de saturação na paisagem a partir de dados de transmissividade obtidos em campo na bacia hidrográfica do rio Jardim (DF). Revista Espaço e Geografia. Vol. 12, nº. 1., p. 105- 123.

ERSKINE, R. H.;GREEN, T. R.;RAMIREZ, J. A.;MACDONALD, L. H.2006, Comparison of grid-based algorithms for computing upslope contributing area. Water Resourses Research. $\mathrm{n}^{\circ} 42$.

FORNARI, A. Geologia e metalogênese da porção meridional do Cráton Luís Alves/SC. 1998. 136p. Tese (Doutorado em Geociências). Programa de Pós-Graduação em Geociências da Universidade de Campinas. São Paulo.

FREITAS, L. F. Análise da Influência das Alterações da Rede de Drenagem Devida a Urbanização no Desenvolvimento de Voçorocas em Quatro Regiões do Distrito Federal. 2012. 108 f. Dissertação (Mestrado em Geografia) - Instituto de Ciências Humanas, Universidade de Brasília, Brasília, Distrito Federal, 2012.

GOMES R.A.T., GUIMARÃES R.F., CARVALHO JÚNIOR O.A., FERNANDES N.F. 2004, Análise da influência da escala cartográfica no resultado de um modelo de previsão de áreas críticas a deslizamentos, Ciência e Natura, v.1, p. 269-286.

GRUBER, S., AND PECKHAM, S. 2009, Land-surface parameters and objects in hydrology. In:Hengl, T., and Reuter, H.I. (Eds.): Geomorphometry: Concepts, Software, Applications.p. 171-194. Elsevier, Amsterdam.

LUIZ, E. L. 2003, Influência da dinâmica hidrológica e das características das formações superficiais nos mecanismos de ruptura das encostas com rochas granitoides de áreas subtropicais- São Pedro de Alcântara, Tese (doutorado em Geografia), Universidade Federal do Rio de Janeiro, Rio de Janeiro,238p.

LUIZ, E. L.; GERENTE, J; GASPER, B. De; BINI, G. M. P. Discussão dos condicionantes e mecanismos de um deslizamento no município de Luís Alves, Santa Catarina. In: X Simpósio Nacional de Geomorfologia, 2014, Manaus. Anais.

MARTZ, L. W., GARBRECHT, J. 1992. Numerical definition of drainage network and subcatchment areas from digital elevation models. Computers and Geosciences, 18(6), 747-761.

MONTGOMERY D. R., DIETRICH W. E. 1994, A physically based model for the topographic control on shallow landslide,Water Resources Research,n. 30, p. $1153-1171$.

O'CALLAGHAN, J.F.; MARK, D.M. 1984, The extraction of drainage networks from digital elevation data. Computer vision, graphics, and image processing, n. 28, p 323-344.

O’LOUGHLIN, E. M. 1986, Prediction of surface saturation zones in natural catchments by topographic analysis, Water Resources Research, Washington, v. 22, p. 794-804.

QUINN, P., BEVEN,K., CHEVALLIER,P., PLANCHON, O.1991, The prediction of hillslope flow paths for distributed hydrological modeling using digital terrain models, Hydrol. Processes, $\mathrm{n}^{\circ}$ 5, p. 59-79.

RAMOS, V. M., GUIMARÃES, R. F., REDIVO, A. L.; CARVALHO JÚNIOR, O. A. de, FERNANDES, N. F; GOMES, R. A. T. 2003, Avaliação de metodologias de determinação do cálculo de áreas de contribuição. Revista Brasileira de Geomorfologia, 4 (2),p.41-49.

SANTI, C. B. 2004, Processo de Uso e Ocupação do Solo e modelagem de previsão de zonas saturadas no relevo: Subsídio para o estudo de enchentes (Maciço Madureira, Nova Iguaçu, RJ). Dissertação (Mestrado em Geografia),Universidade Federal do Rio de Janeiro,Rio de Janeiro,96p.

TARBOTON, D. G. 1997, A new method for the determination of flow directions and upslope areas in grid digital elevation models, Water Resources Research, no 33, p. 309-319.

TEIXEIRA, M. A. C.2012, Avaliação da suscetibilidade à ocorrência de deslizamentos translacionais superficiais: Utilização de modelos matemáticos de base física na Bacia de Tibo, Arcos de Valdevez. Dissertação de Mestrado, Universidade do Porto. 